\title{
OBITUARY
}

\section{YAROSLAV STEPANOVICH PIDSTRIGACH}

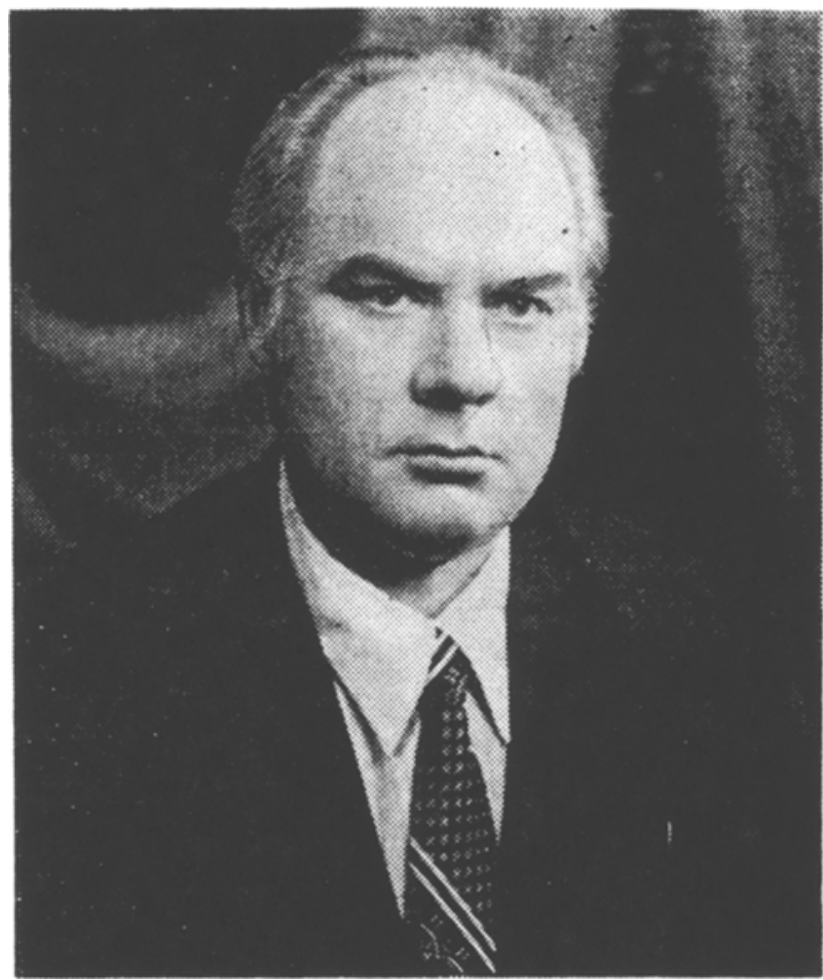

Yaroslav Stepanovich Pidstrigach

Ukrainian science has suffered a severe loss. Yaroslav Stepanovich Pidstrigach died suddenly in his 63rd year, which has meant that we have lost an outstanding scientist, the recipient of the State Prize of the Ukrainian SSR, an activist in science in the Ukraine, the head of the Western Scientific Center, a member of the Presidium of the Academy of Sciences of the Ukrainian SSR, and the director of the Institute of Applied Mechanics and Mathematics, Ukrainian Academy of Sciences. He was also an academician under the Ukrainian Academy of Sciences.

He graduated in 1951 from Ivan Franko L'vov University and entered the Institute of Machine Science and Automatics, Ukrainian Academy of Sciences, which is now called the Karpenko Physicomechanics Institute, where he progressed from graduate student to deputy director. In 1972, under his initiative, the L'vov Branch of the Mathematics Institute, Ukrainian Academy of Sciences, was opened, which in 1978 formed the basis of the Institute of Applied mechanics and mathematics, Ukrainian Academy of Sciences, of which he was the director until the end of his life. Under his guidance, the institute became one of the leading scientific centers in the republic.

His scientific researches were directed to the mechanics of deformable solids. His theoretical papers on numerous topics in that field were pioneering in character and attracted wide-ranging attention from the scientific community. He founded and guided an original school of thermodynamic simulation, which dealt with various types of physical problems. The scientific results have practical consequences in mechanics, geophysics, and advanced technology.

Translated from Fiziko-Khimicheskaya Mekhanika Materialov, Vol. 26, No. 3, pp. 129-130, May-June, 1990. 
During his work at the Western Scientific Center of the Ukrainian Academy of Sciences, he did much to organize combined researches on topics important to the economy of the region, environmental protection, and the general use of control methods in applying scientific advantages in the national economy.

This talented individual, outstanding teacher, and leader constantly devoted considerable effort to training and guiding young scientific workers. Over $50 \mathrm{D} . \mathrm{Sc}$. and Ph.D. degrees have been awarded under his direction.

He was an active citizen as well as scientist and teacher, and for these numerous activities on behalf of the State he received the Rrylov Prize of the Ukrainian Academy of Sciences.

We have lost an outstanding teacher and talented organizer of science, who devoted all his life to the development and enrichment of the intellectual potential of his native land.

Thr bright memory of him will always remain in the hearts of those who knew him and worked with him.

Ukrainian Academy of Sciences

Western Scientific Center

Karpenko Physicomechanics Institute

Editorial Board and editors of Physicochemical

Mechanics of Materials 